containing 0.5 to 1 per cent of $\mathrm{H}_{2} \mathrm{O}^{18}$. The water so obtained (or the oxygen prepared from it) will be used as an 'isotopic indicator' in reactions involving oxygen. A specimen of such water prepared by Hertz has already been used to investigate the mechanism of saponification of esters (Polanyi and Szabo: Trans. Faraday Soc., 30, 508 ; 1934.)

\section{The Naturalist in the Laboratory}

Sir Frederick Gowland Hopkins delivered the Bacot Memorial Lecture entitled "The Naturalist in the Laboratory" before the London Natural History Society on April 2. Sir Frederick pointed out that early biology was limited to study of the physiology and morphology of plants and animals (chiefly vertebrates), the causes which affected them being largely conjectural ; the chemist provided means of elucidating these problems. Observation of the bombardier beetle and its explosive excretion first attracted Sir Frederick's notice to these matters fifty seven years ago, and despite this first experiment proving fruitless, it was this which led to his taking up biochemistry. The work of the biochemist in comparing the action of catalysis with enzymes has established the processes at work which enable both plant and animal to digest and transform food materials into substances suitable for oxidation to enable life to continue. But it does not stop there, for it has shown the relationship between species by the parallel processes carried on in similar species, and that each species may have its own process. A further stage has been to show the necessity for certain substances to allow the full utilisation of food supplies. Known as vitamins, they provide the means for the body to obtain enough fuel to supply full growth and reduce vulnerability to disease. Although systematic, taxonomic, morphological and physiological research must continue, and the biochemist can still open new avenues for exploration, there is every scope for wide co-operation between all branches of natural history from an ecological point of view. Finally, although exact chemical reactions in plant and animal can be ascertained and reproduced experimentally, and although living tissues can be made to function under artificial conditions, the origin and nature of life is a matter which scientific research has yet to explain.

\section{A New Wind Tunnel}

THE new 24-ft. wind tunnel at the Royal Aircraft Establishment, Farnborough, opened by the Secretary of State for Air on April 5, is the largest in Great Britain. It can contain a complete aeroplane, all of the machine except the outer portions of the wings being in the air stream and under observation. Air speeds equivalent to 115 miles per hour are obtained. The principal immediate use of this type of tunnel is the investigation of 'interference' between various bodies in juxtaposition, such as airscrews and engine cowlings, which cannot be studied precisely upon small-scale models. Such problems cannot be examined as fully as is necessary in actual flight owing to the uncertainty of the steadiness of the air at the moment of taking an observation, and moreover, such experimental flying with new and untried design ideas involves considerable risk, and often delay, in bad weather. This tunnel is not the largest in the world, there being a $60 \mathrm{ft} . \times 30 \mathrm{ft}$. one at Langley Field, United States, and a $50 \mathrm{ft}$. span one in France (see Nature, Feb. 16, 1935, p. 252). It is interesting to note that one of the first machines to be investigated in this channel will be a new one that has exceeded its anticipated performance in certain respects by so much as to shake confidence in the accepted methods of estimating the total air resistance of combinations of differently shaped bodies.

\section{Shortt Clock at the Science Museum}

A SHoRTT free pendulum clock has recently been installed at the Science Museum, South Kensington, and is now at work controlling the main public dials of the Museum. The Shortt clock was perfected by Mr. W. H. Shortt in 1921 as a result of a long period of experimental work in association with Mr. F. Hope-Jones and the Synchronome Company; the first elock was set up at the Edinburgh Royal Observatory in 1921, and Prof. R. A. Sampson's report on its first year's run aroused great interest among astronomers, as it had proved to have surpassed all previous clocks in its accuracy. A Shortt clock was adopted as the sidereal standard at Greenwich at the beginning of 1925, and has proved itself capable of measuring time to an accuracy of a few thousandths of a second per day, or better than 1 in $10^{7}$. The clock now exhibited in the Science Museum is identical with these observatory clocks except that the usual exhausted copper case for the free pendulum is replaced by a dust-tight glass cylinder : the clock is mounted on the wall of a public gallery with its slave elock by its side. The delicate method of imparting an impulse to the free pendulum and the action of the hit-and-miss synchroniser can thus be studied in detail.

\section{Excavations at Jericho, 1934-35}

Durrvg the season which has just closed, Sir Charles Marston's archæological expedition to Jericho, of which Prof. John Garstang is field director, has penetrated to the neolithic levels of earliest occupation which, it is found, cover a considerable portion of the site, under deposits of the Early Bronze Age measuring $27 \mathrm{ft}$. thick. In the neolithic levels, forming a layer $18 \mathrm{ft}$. deep, were found sealed deposits in the form of a series of superimposed house structures, in which the floors had been plastered, coloured red, and burnished. There is evidence to show that the walls of these structures had been treated in a similar fashion. One of the most interesting finds, according to a dispatch reporting the results of the excavation in The Times of April 4, is the head of a cult image of human form made of unbaked clay, in which the eyes are represented by shells. It was found in association with sherds of Thessalian painted pottery and fragments of primitive local ware imme. diately below the Early Bronze Age levels. The flint 